\title{
Corallimorpharians are not "naked corals": insights into relationships between Scleractinia and Corallimorpharia from phylogenomic analyses
}

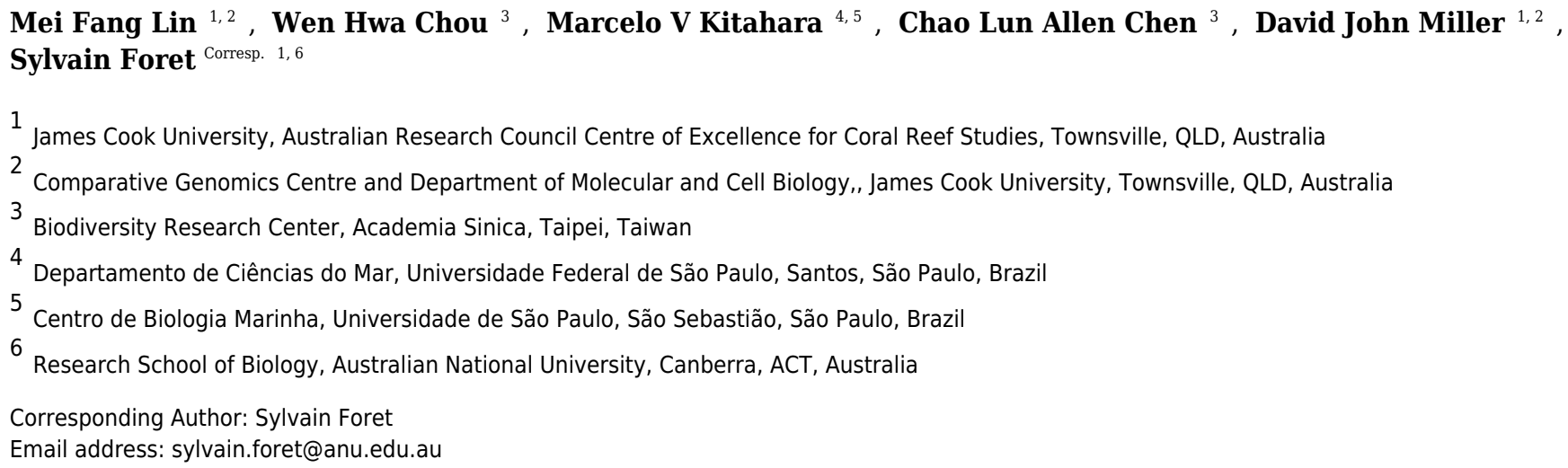

Calcification is one of the most distinctive traits of scleractinian corals. Their hard skeletons form the substratum of reef ecosystems and confer on corals their remarkable diversity of shapes. Corallimorpharians are non-calcifying, close relatives of scleractinian corals, and the evolutionary relationship between these two groups is key to understanding the evolution of calcification in the coral lineage. One pivotal question is whether scleractinians are a monophyletic group, paraphyly being an alternative possibility if corallimorpharians are corals that have lost their ability to calcify, as is implied by the "naked-coral" hypothesis. Despite major efforts, relationships between scleractinians and corallimorpharians remain equivocal and controversial. Although the complete mitochondrial genomes of a range of scleractinians and corallimorpharians have been obtained, heterogeneity in composition and evolutionary rates means that mitochondrial sequences are insufficient to understand the relationship between these two groups. To overcome these limitations, transcriptome data were generated for three representative corallimorpharians. These were used in combination with sequences available for a representative range of scleractinians to identify 291 orthologous single copy protein-coding nuclear markers. Unlike the mitochondrial sequences, these nuclear markers do not display any distinct compositional bias in their nucleotide or amino-acid sequences. A range of phylogenomic approaches congruently reveal a topology consistent with scleractinian monophyly and corallimorpharians as the sister clade of scleractinians. 
1 Corallimorpharians are not "naked corals": insights into relationships between

2 Scleractinia and Corallimorpharia from phylogenomic analyses

3

4 Mei-Fang Lin ${ }^{1,2}$, Wen-Hwa Chou ${ }^{3}$, Marcelo V. Kitahara ${ }^{4,5}$, Chaolun Allen Chen ${ }^{3}$, David J.

5 Miller $^{1,2, *}$, Sylvain Forêt ${ }^{1,6 *}$

6

$7 \quad{ }^{1}$ ARC Centre of Excellence for Coral Reef Studies, James Cook University, Townsville,

8 Australia

$9{ }^{2}$ Comparative Genomics Centre and Department of Molecular and Cell Biology, James

10 Cook University, Townsville, Australia

11 33iodiversity Research Centre, Academia Sinica, Taipei, Taiwan

12 를

13 Brazil

$14{ }^{5}$ Centro de Biologia Marinha (CEBIMar), Universidade de São Paulo, São

15 Sebastião, Brazil

$16{ }^{6}$ Research School of Biology, Australian National University, Canberra, Australia

17

18 Corresponding authors: $\underline{\text { david.miller@j,jcu.edu.au, sylvain.foret } @ \text { anu.edu.au }}$ 


\section{Abstract}

21 Calcification is one of the most distinctive traits of scleractinian corals. Their hard skeletons

22 form the substratum of reef ecosystems and confer on corals their remarkable diversity of shapes.

23 Corallimorpharians are non-calcifying, close relatives of scleractinian corals, and the

24 evolutionary relationship between these two groups is key to understanding the evolution of

25 calcification in the coral lineage. One pivotal question is whether scleractinians are a

26 monophyletic group, paraphyly being an alternative possibility if corallimorpharians are corals

27 that have lost their ability to calcify, as is implied by the "naked-coral" hypothesis. Despite

28 major efforts, relationships between scleractinians and corallimorpharians remain equivocal and

29 controversial. Although the complete mitochondrial genomes of a range of scleractinians and

30 corallimorpharians have been obtained, heterogeneity in composition and evolutionary rates

31 means that mitochondrial sequences are insufficient to understand the relationship between these

32 two groups. To overcome these limitations, transcriptome data were generated for three

33 representative corallimorpharians. These were used in combination with sequences available for

34 a representative range of scleractinians to identify 291 orthologous single copy protein-coding

35 nuclear markers. Unlike the mitochondrial sequences, these nuclear markers do not display any

36 distinct compositional bias in their nucleotide or amino-acid sequences. A range of

37 phylogenomic approaches congruently reveal a topology consistent with scleractinian monophyly and corallimorpharians as the sister clade of scleractinians. 


\section{Introduction}

43 Scleractinian corals are the subject of intense scientific, public and, therefore, media interest, 44 particularly because of the uncertain fate of coral reefs in the face of ever increasing

45

46

47

48

49

50

51

52

53

54

55

56

57

58

59

60

61

62

63

64

65

66

67

68

69

70

71

72 anthropogenic challenges (Done 1999; Hughes 2003; Hughes et al. 2003). Due to their capacity to deposit massive continuous calcareous skeletons, the coral reef framework built by scleractinians provides one of the most complex and diverse of biological habitats (Cohen \& Holcomb 2009). Despite their ecological importance and our economic dependence on them (Moberg \& Folke 1999), we know remarkably little about the evolutionary history of this animal group. This lack of understanding limits our ability to predict how corals, and therefore the diverse habitats that they support, will respond to climate change and ocean acidification (OA). Although the vast majority of scleractinian fossils post-date the sudden appearance of diverse coral families 14 My after the Permian/Triassic boundary, there is now evidence that the evolutionary origin of the group is rooted deep in the Paleozoic. In brief, molecular clock estimates calibrated using the earliest fossils that can be unambiguously assigned to extant clades, and whose unique skeletal characters can be unequivocally recognized in fossil coralla, imply that the scleractinian corals originated from a non-skeletonized ancestor in the Ordovician (Stolarski et al. 2011). When considered in conjunction with the elusive Paleozoic fossil record of the scleractinian lineage (Ezaki 1997; Ezaki 2000; Scrutton \& Clarkson 1991), this suggests that either the fossil record for the period between the Ordovician and late Permian is yet to be discovered, or that skeleton formation may be an ephemeral trait within the Scleractinia (Stanley \& Fautin 2001).

3 The idea that the ability of corals to deposit a skeleton may be an ephemeral trait on evolutionary 4 time scales, the presence or absence of a calcareous skeleton potentially reflecting prevailing environmental conditions, together with the anatomical similarity of Actiniaria, 6 Corallimorpharia, and Scleractinia (Daly et al. 2007; Stanley \& Fautin 2001), led Stanley 7 (Stanley 2003) to propose the "naked coral" hypothesis (figure 1a). The central idea of this 8 hypothesis is that "different groups of soft-bodied, unrelated anemone-like anthozoans gave rise 9 to various calcified scleractinian-like corals through aragonitic biomineralization" (Stanley 0 2003), potentially explaining the sudden appearance of a diverse and differentiated range of 1 scleractinian skeletal types in the Triassic. Under this hypothesis, the scleractinian skeleton is not 2 a synapomorphy, but stands for an organization grade. Consistent with this hypothesis, the 
73 Scleractinia were paraphyletic in molecular phylogenetic analyses based on amino acid (aa)

74 sequence data from mitochondrial protein-coding genes (Medina et al. 2006). In these analyses,

75 it was estimated that corallimorpharians - anthozoans without a skeleton - diverged from the

76 Robust scleractinian clade during the late- and mid-Cretaceous, implying that corallimorphs were

77 descended from a coral that had undergone skeleton loss during a period of increased ocean

78 acidification. Whilst ocean acidification events occurred in that period they did not cause any

79 reef crisis (Honisch et al. 2012; Kiessling et al. 2010; Pandolfi et al. 2011). Moreover, some

80 alternative phylogenetic analyses based on a range of other molecular markers (Chen et al. 2002;

81 Fukami et al. 2008; Lin et al. 2014; Romano \& Palumbi 1996) did not support the naked coral

82 senario, and it has become apparent that mitochondrial sequence data might not be appropriate

83 for the elucidation of phylogenetic relationships within the Corallimorpharia/Scleractinia clade

84 (Kitahara et al. 2014).

85 The issue of coral/corallimorpharian relationships is of particular importance, because the idea

86 that skeleton loss can occur as a consequence of ocean acidification carries implications for the

87 future of corals and coral reefs under climate change and elevated atmospheric [CO2]. A better

88 understanding of coral evolution more broadly has further implications for coral reef futures. For

89 instance, it is important to understand how prior OA events (Kiessling et al. 2010) have impacted

90 the scleractinian lineage, and the underlying causes of previous "reef crises" (Hoegh-Guldberg et

91 al. 2007).

92 In order to shed light on the relationship between Corallimorpharia and Scleractinia,

93 phylogenomic analyses were carried out based on 291 single-copy nuclear protein-coding genes

94 from a representative range of robust and complex corals, corallimorpharians, and sea anemones.

95 To enable the phylogenomic analysis, it was first necessary to generate comprehensive

96 transcriptome assemblies for the three corallimorpharian species - Rhodactis indosinensis,

97 Ricordea yuma and Corynactis australis. These molecular data constitute an important resource

98 for this neglected animal group. Analyses were carried out both at the amino acid and nucleotide

99 levels on concatenated, partitioned and individual alignments using multiple inference methods.

100 The results provide strong support for scleractinian monophyly, allowing rejection of the

101 hypothesis that corallimorpharians are "naked corals" - descendants of a scleractinian that had

102 undergone skeleton loss. 


\section{Materials and methods}

105 Transcriptome assembly and data matrix

106 The complete workflow from data collection to analysis is summarized in figure S1. The

107 taxonomic sampling (table S1) included three "Complex" corals from two families, six "Robust"

108 corals from five families, three corallimorpharians representing three families, and two

109 actiniarians. Gorgonia ventalina was used as the outgroup. The new corallimorpharian

110 transcriptome data were obtained from two zooxanthellate species (Ricordea yuma and

111 Rhodactis indosinensis) and an azooxanthellate species (Corynactis australis). Ricordea yuma

112 samples were collected from the Great Barrier Reef (18²5'35.20"S, 146 41'10.91"E).

113 Corynactis australis colonies were collected from Jervis Bay, New South Wales $\left(35^{\circ} 4^{\prime} 14.11^{\prime \prime S}\right.$,

$\left.114150^{\circ} 41^{\prime} 48.20^{\prime \prime} \mathrm{E}\right)$. The Rhodactis indosinensis samples were collected at Beitou fishing harbor,

115 Keelung, Taiwan. The transcriptomes were generated from purified RNA extracted by using

116 Trizol Reagent (Invitrogen, USA) and dissolved in RNase-free water. High throughput

117 sequencing was conducted using the Illumina HiSeq 2000 platform. The transcriptomes were

118 then assembled with Trinity (r2013_08_14) using default settings (Grabherr et al. 2011).

119 Symbiodinium sequences were eliminated using PSyTranS

120 (https://github.com/sylvainforet/psytrans). The resulting contigs were clustered with CD-HIT-

121 EST (Li \& Godzik 2006) at a sequence similarity threshold of 0.9. The contigs were then

122 translated into amino acid sequences with TransDecoder (Grabherr et al. 2011). A summary of

123 the resulting transcritpome assemblies is given in table $\mathrm{S} 2$. The raw reads and the transcriptome

124 assemblies have been deposited to NCBI under BioProject PRJNA313487.

125 HaMStR v13.2 (Ebersberger et al. 2009) was used to search for orthologs using three

126 available cnidarian genomes as primer taxa, Acropora digitifera (Shinzato et al. 2011),

127 Nematostella vectensis (Putnam et al. 2007) and Hydra magnipapillata (Chapman et al. 2010),

128 with $A$. digitifera as the reference taxon, resulting in 1,808 core orthologs. The same program

129 was used for an extended search for orthologs in the other scleractinians, corallimorpharians, and

130 actiniarian transcriptomes. The H. magnipapillata sequences were excluded from the

131 phylogenetic analyses due to their very high divergence with the Anthozoan sequences. In the

132 end, we identified 291 one-to-one orthologs across all 15 taxa. Each orthologous group was

133 annotated according to the best blast hit of the A. digitifera protein in that cluster against the

134 NCBI nr database with an e-value cut-off of 1e-5. 
135 The amino acid (aa) sequences from the 291 orthologous genes were aligned using

136 MAFFT L-INSI v7.13 (Katoh \& Standley 2013) and subsequently trimmed using trimAl v1.2

137 with the Heuristic method (Capella-Gutierrez et al. 2009). The nucleotide (nt) alignments were

138 deduced from the aa alignments as described in (Kitahara et al. 2014). The saturation at each

139 nucleotide was estimated with DAMBE v5.3.110 (Xia 2013), revealing no significant saturation

140 in the dataset (table S3).

141

142 Supermatrix phylogeny

143 For the concatenated aa matrix, the best fitting model determined using ProtTest v3

144 (Darriba et al. 2011) was JTT + G + I. Maximum likelihood (ML) analyses were carried out with

145 RAxML v7.2.6 (Stamatakis 2006) using rapid bootstrapping (-f a). Phylogenies based on the

146 supermatrix were also computed using Bayesian inference (BI) with PhyloBayes MPI v1.5a

147 (Lartillot et al. 2013) using the JTT $+\mathrm{G}+\mathrm{I}$ model. Identical topologies were recovered with CAT-

148 Possion, and CAT+GTR models. Each run contained four chains and ran until convergence.

149 Convergence was assessed after a burn-in period of 2,000 generations following the author's

150 guidelines (maxdiff $<0.1$ and effective size $>300$ ). The best fitting model for the nt alignment

151 determined by jModelTest 2 (Darriba et al. 2012) was the GTR+G+I, and the phylogenetic

152 inference was carried out in a similar way as the aa analysis. Trees and alignments have been

153 deposited to TreeBase (ID 19254).

154

\section{Partitioned phylogeny}

156 Partitions and their corresponding best-fitting models were identified using PartitionFinder

157 (Lanfear et al. 2012) with the relaxed clustering algorithm, checking the top 1\% schemes. ML

158 analysis was conducted on the partitioned datasets using RAxML v7.2.6 (Stamatakis 2006) with

159100 bootstrap replicates. The partitions identified by Partition finder were also used for Bayesian

160 inference using MrBayes v3.2.3 (Ronquist \& Huelsenbeck 2003) with 4 runs, 2 million

161 generations saving topologies each 1,000 generations and discarding the first $25 \%$ generations as

162 burn-in.

163

164 Concordance factor estimation 
165 Concordance factors were estimated on the 291 individual topologies inferred by MrBayes 166 v3.2.3 (Ronquist \& Huelsenbeck 2003) (four runs, 2 million generations 25\% burn-in) using 167 BUCKy (Ane et al. 2006) with default settings $(\alpha=1)$. 


\section{Results and Discussion}

170 Analyses of the concatenated nucleotide supermatrix

171 The data matrix for the 15 taxa (table S1) comprised 291 nuclear protein-coding genes, 263 of

172 which have functional annotations, the other 28 coding for unknown proteins (table S5) that

173 probably correspond to cnidarian- or anthozoan-specific genes. The final alignment of the

174 nucleotide sequences contained 370,809 positions, around 30 times longer than in the previously

175 published phylogenies based on whole mitochondrial genomes (Kitahara et al. 2014). A ML

176 phylogeny was inferred using the best fitting model $(\mathrm{GTR}+\mathrm{G}+\mathrm{I})$, resulting in a topology

177 consistent with scleractinian monophyly and with a bootstrap support of $100 \%$ for every node

178 (table 1). This result is consistent with analyses based on the nucleotide sequences of

179 mitochondrial protein-coding genes (Fukami et al. 2008; Kitahara et al. 2010; Kitahara et al. 180 2014).

181 To take into account the fact that different regions of the alignment can evolve at different

182 rates and according to different models, the aa supermatrix was partitioned using PartitionFinder,

183 by gene and by codon, resulting in 75 and 106 partitions respectively. ML and BI phylogenies

184 were then inferred for each partitioning scheme, all strongly supporting scleractinian monophyly

185 (table 1). Thus, both unpartitioned and partitioned analyses of the nucleotide supermatrix

186 consistently support the monophyly of Scleractinia. These findings corroborate a number of

187 previous studies (e.g.: (Fukami et al. 2008; Kitahara et al. 2010; Kitahara et al. 2014; Lin et al.

188 2014; Stolarski et al. 2011)). However, as analyses of mitochondrial protein-coding sequences at

189 the amino acid and nucleotide levels result in distinct tree topologies (Kitahara et al. 2014;

190 Medina et al. 2006), ML and BI analyses were also conducted based on the aa sequences of the

191 nuclear protein-coding genes.

192

193 Analyses of the concatenated amino acid supermatrix

194 The concatenated amino-acid alignment consisted of 122,170 positions. Both ML and BI

195 methods generated phylogenetic trees in which all nodes were strongly supported (table 1). In the

196 ML reconstruction, all the bootstrap values were $>70 \%$ and most nodes had $100 \%$ support. In the

$197 \mathrm{BI}$ analysis, the posterior probability for all the nodes was $100 \%$. Partitioning of the amino acid

198 alignment resulted in 153 subsets. ML and BI phylogenies were then inferred based on the best

199 substitution model for each partition (table S6) and also strongly supported the monophyly of 
200 scleractinians (table 1). In summary, unpartitioned and partitioned analysis of nuclear markers at

201 the amino-acid and nucleotide level are congruent. The major implication of these analyses of

202 nuclear sequence data is that corallimorpharians are not scleractinians that have

203 undergone skeleton loss (figure 1a). However, a ML tree based on the mitochondrial

204 proteins of a set of species close to those used for nuclear markers recovered the naked

205 coral topology (figure S2), consistent with the results reported by (Kitahara et al. 2014),

206 which could be a result of the sequence composition biases in these mitochondrial

207 genomes.

208

209 Sequence composition

210 In the case of mt genomes, significant differences in the base composition of protein coding

211 genes were observed between corallimorpharians, robust and complex corals, resulting in

212 different patterns of codon usage and amino acid composition across the various lineages

213 (Kitahara et al. 2014). In order to investigate the potential for compositional bias to affect the

214 topology recovered for nuclear protein-coding genes, base composition was estimated for each of

215 the 15 taxa included in the present analyses (table S4). Base composition was generally similar

216 across all the hexacorallian groups, but the octocoral $(\mathrm{A}+\mathrm{T})$ content $(57.96 \%)$ was significantly

217 higher. Within the Hexacorallia, the complex scleractinian clade had the highest $(\mathrm{A}+\mathrm{T})$ content

$218(56.5 \%)$ and, consequently, a higher proportion of (A+T)-rich aa (FYMINK). The remaining

219 groups (i.e.: Actiniaria and Scleractinia [Robusta clade]) displayed an overall (A+T) content

220 between 55.00 and 55.95\% and no major differences between FYMINK and $(\mathrm{G}+\mathrm{C})$-rich aa

221 (GARP) (figure S3). The thymine and cytosine contents of nuclear protein coding genes of

222 Robusta differed slightly $(<1 \%)$ across all three codon positions compared to other

223 scleractinians,. The nuclear protein-coding genes of Actinaria, Corallimorpharia and Scleractinia

224 have therefore a very similar composition (figure S3). In comparison to proteins encoded by the

225 mitochondrial genome, nuclear-encoded proteins of anthozoans contain, in general, more lysine

226 (7\% vs $2 \%)$, aspartic acid (5.5\% vs $2 \%)$, and glutamic acid (7\% vs $2.5 \%)$ residues, but

227 significantly less phenylalanine (4\% vs $8 \%$, and $13 \%$ in robust corals).

228 Major differences in the composition of mitochondrial protein-coding genes at both the

229 nucleotide and amino acid levels support the idea that the mitochondrial genomes of robust

230 corals are evolving at a different rate to those of other hexacorallians (Aranda et al. 2012; 
231 Fukami \& Knowlton 2005; Kitahara et al. 2014). However, no such compositional biases appear

232 to hold for nuclear protein-coding genes, implying that these nuclear sequences are more

233 appropriate sources of phylogenetic information than mitochondrial data (Kitahara et al. 2014).

234

235 Analysis of individual gene topologies

236 Genes at different genomic locations may have distinct evolutionary histories, and thus different

237 topologies may be recovered (Akanni et al. 2014; Ane et al. 2006; Pisani et al. 2007). We

238 constructed trees based on individual genes using ML and BI and explored the distribution of the

239 various topologies. For all types of inference scleractinian monophyly was recovered by the

240 majority of genes, while only a small proportion of the trees were concordant with the naked

241 coral hypothesis (figure 2a ). The patterns of topologies for each tree across all types of inference

242 was then investigated. Again, the most common pattern was genes producing scleractinian

243 monophyly across all types of inference, while only a few genes were consistent with the naked

244 coral hypothesis for all the reconstruction methods (figure 2b). A sizeable proportion of genes

245 did not agree with either scenario, as can be expected when inferring such deep relationships

246 based on single markers. A search for systematic differences between the genes supporting the

247 two competing of topology did not reveal any differential Gene Ontology enrichment. However,

248 genes supporting the naked coral topology for all types of inference were found to be

249 significantly shorter than genes supporting the alternative topology (figure $2 \mathrm{c}$ ). This suggests that

250 genes supporting the naked coral hypothesis might be too small for the inference of the correct

251 topology.

252 Bayesian Concordance Analysis was then used to evaluate the contribution of individual genes to

253 the final topology in the BI trees. High concordance factor (CF) values on branches indicate

254 support from multiple genes (Weisrock, 2012). The primary topology recovered by concordance

255 analysis supported scleractinian monophyly (figure S4). In particular, the branches descending

256 from the split between Scleractinia and Corallimorpharia have mean sample-wise CF values of

2570.627 and 0.756 respectively. This result is consistent with the unpartitioned and partitioned

258 analyses of the concatenated sequence data and therefore indicates broad support across the

259 sampled nuclear genes for the monophyly of scleractinians.

260

261 Are corallimorpharians naked corals? 
262 Comparisons based on mitochondrial genomic architecture (Lin et al. 2014) suggest that

263 corallimorpharians are derived from an azooxanthellate ancestor. Anatomical similarities

264 between scleractinians and corallimorpharians support a close relationship between them, but

265 corallimorpharians not only lack mineralized skeletons, but also differ from scleractinians in

266 terms of several characters - for example: the condition of the mesoglea, tentacular arrangement

267 and the presence of homotrichs in the tentacles (den Hartog 1980). Systematically, the

268 taxonomic rank of Corallimorpharia has been controversial (Budd et al. 2010; Daly et al. 2003;

269 den Hartog 1980; Medina et al. 2006; Romano \& Cairns 2000). The phylogenomic analyses

270 presented here provide strong support for scleractinian monophyly, and allow rejection of the

271 idea that the corallimorpharian lineage was derived from corals by skeleton loss. The analyses

272 supporting this latter idea were based on amino acid sequence data from mitochondrial genomes

273 (Medina et al. 2006), but it is now clear there are fundamental problems in using mitochondrial

274 data to infer phylogenetic relationships amongst hexacorallians (Kitahara et al. 2014), as is also

275 the case in beetles (Sheffield et al. 2009) and some groups of mammals (Huttley 2009).

276

277 Insights into coral evolution

278 Taking into account the fossil and published molecular data (Kiessling et al. 2010; Stolarski et al.

279 2011), the analyses above imply that the ability to secrete a skeleton was acquired early in

280 scleractinian evolution, but was followed by multiple origins of skeleton complexity in various

281 subclades (Romano \& Cairns 2000). The Paleozoic fossil record (Ezaki 1997; Ezaki 1998;

282 Scrutton 1993; Scrutton \& Clarkson 1991) and molecular data (Stolarski et al. 2011) both imply

283 that the earliest scleractinians were solitary and inhabited deep water and therefore lacked

284 photosynthetic symbionts. The sudden appearance of highly diversified forms of Scleractinia

285 about $14 \mathrm{Ma}$ after the end-Permian extinction (the "Great Dying" (Roniewicz \& Morycowa

286 1993; Stanley 2003; Veron 1995; Wells 1956)) might be explained by multiple independent

287 origins from deep-water ancestors (e.g. the family Agariciidae (Kitahara et al. 2012)). It thus

288 appears likely that the acquisition of photosynthetic symbionts and the development of

289 coloniality have probably both occurred independently on multiple occasions (but see Barbeitos

290 et al, 2010), resulting not only in a wide range of skeletal phenotypes but also in habitat

291 expansion, which has played important roles in the formation of shallow-water reefs. 
292 It has been demonstrated that, when maintained under acidic conditions ( $\mathrm{pH} 7.3-7.6)$, at least 293 some corals can survive for 12 months after undergoing skeleton loss, recovering fully after 294 return to normal seawater (Fine \& Tchernov 2007). One interpretation of these experiments is 295 that, during evolution, the coral lineage might have been able to alternate between soft and 296 skeletonized forms, potentially explaining the gaps in the fossil record. However, the fact that 297 corallimorpharians are not derived from corals, and the monophyly of extant Scleractinia, 298 suggests otherwise - that skeleton-less corals are not viable on evolutionary time scales. This has 299 important implications for the future of the coral lineage - the evolutionary resilience of the 300 Scleractinia may have depended in the past on deep sea refugia, as most of the "reef crises" have 301 coincided with rapid increases in both OA and sea surface temperature (Pandolfi et al. 2011).

302 Deep-sea corals would have escaped the challenges of high SST, thus the coral lineage may have 303 been able to re-establish itself in the shallows when more favourable conditions returned. At the 304 present time, unprecedented rates of increase in OA and SST are occurring concurrently with 305 massive disruption of deep-sea habitats caused by deep sea trawling, prospecting and mining 306 (Guinotte et al. 2006; Ramirez-Llodra et al. 2011; Barbier et al. 2016). Is the resilience of the 307 Scleractinia as a lineage therefore at risk?

308

309 Acknowledgements

310 The authors thank Allen Collins and an anonymous reviewer for their valuable comments on the 311 manuscript, Mr. Chris Benstead (Reef HQ Aquarium), Dr. Joshus Madin (Macquarie 312 University), Mr. Chao-Yang Kuo (James Cook University) for the assistance with sampling 313 corallimorpharians and field logistics. 
315 Table 1 Support values of critical nodes (see figure 2 for the numbering of nodes) for ML and BI

316 analyses inferred using unpartitioned and partitioned phylogenetic analyses of amino acid and

317 nucleotide data. The best fitting substitution model for each concatenated unpartitioned dataset is

318 indicated; the best fitting models for the partitioned phylogenies are detailed in table S4.

319 Scleractinian monophyly is fully supported by all the analyses.

320

\begin{tabular}{|c|c|c|c|c|c|c|c|c|c|}
\hline \multirow{4}{*}{$\begin{array}{l}\text { Data type } \\
\text { Method } \\
\text { Supporting value } \\
\text { Matrix type } \\
\end{array}$} & \multicolumn{4}{|c|}{ Amino acid dataset } & \multicolumn{5}{|c|}{ Nucleotide dataset } \\
\hline & \multirow{2}{*}{\multicolumn{2}{|c|}{$\begin{array}{l}\text { Maximum Likelihood analyses } \\
\text { Bootstrap support(\%) }\end{array}$}} & \multirow{2}{*}{\multicolumn{2}{|c|}{$\begin{array}{c}\text { Bayesian Inference } \\
\text { Posterior Probability }\end{array}$}} & \multirow{2}{*}{\multicolumn{3}{|c|}{$\begin{array}{l}\text { Maximum Likelihood analysis } \\
\text { Bootstrap support(\%) }\end{array}$}} & \multirow{2}{*}{\multicolumn{2}{|c|}{$\begin{array}{l}\text { Bayesian Inference } \\
\text { Posterior Probability }\end{array}$}} \\
\hline & & & & & & & & & \\
\hline & Concatenated matrix & Partitions & Concatenated matrix & x Partitions & Concatenated matrix & Partitions by Gene & Partition by Codon & Partitions by Gene & Partition by Codon \\
\hline Selected Nodes/ substition models & $\mathrm{JTT}+\mathrm{G}+\mathrm{I}$ & 153 subsets & $\mathrm{JTT}+\mathrm{G}+\mathrm{I}$ & 153 & GTR+G+I & 75 subsets & 106 subsets & 75 subsets & 106 subsets \\
\hline 1 (Corallimorpharia, Scleractinia) & 100 & 100 & 1 & 1 & 100 & 100 & 100 & 1 & 1 \\
\hline 2 (Corallimorpharia) & 100 & 100 & 1 & 1 & 100 & 100 & 100 & 1 & 1 \\
\hline 3 (Robusta) & 100 & 100 & 1 & 1 & 100 & 100 & 100 & 1 & 1 \\
\hline 4 (Complexa) & 100 & 100 & 1 & 1 & 100 & 100 & 100 & 1 & 1 \\
\hline
\end{tabular}


323 Figure 1 (a) The two competing hypotheses regarding the relationship between Corallimorpharia 324 and Scleractinia: scleractinian monophyly and the "naked coral" topology. Scleractinian

325 monophyly implies that the ability to calcify was acquired in the ancestor of Scleractinia, whilst

326 the naked coral hypothesis requires secondary loss of this trait in the ancestor of

327 Corallimorpharia. (b) Maximum likelihood phylogenetic tree based on the amino acid sequences 328 of 291 nuclear genes from 15 anthozoans with the JTT+GAMMA+I model. The critical nodes

$329(1,2,3$ and 4) are fully supported, as reported in table 1. The same topology was obtained for all 330 the other analyses with equally strong support (see table 1).

331

332

a)
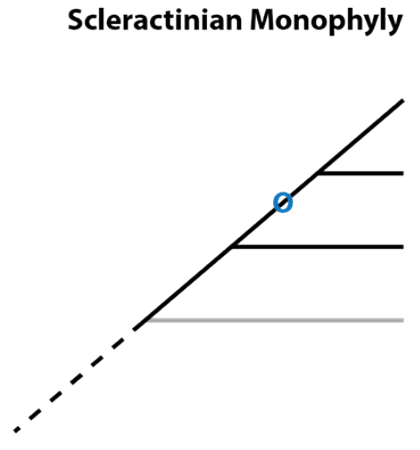

Robust

Complex

Corallimorpharia

Actiniaria

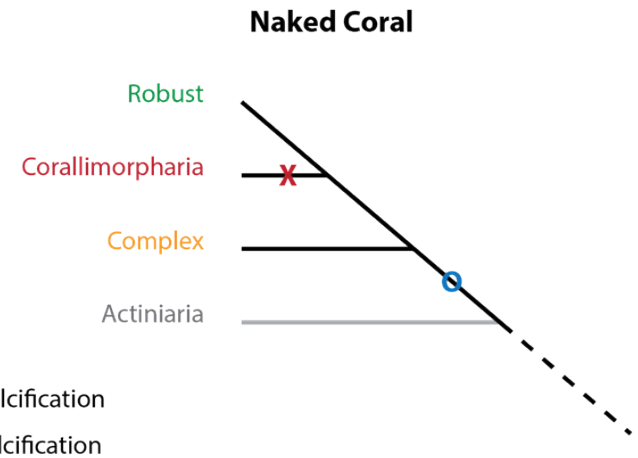

O: Gain of calcification

$\mathbf{X}$ : Loss of calcification
Naked Coral

b)
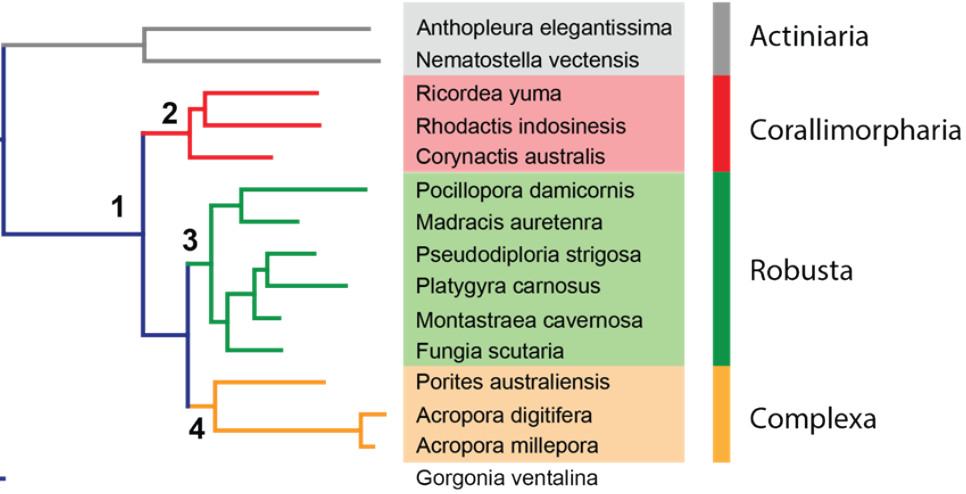
334 Figure 2 (a) Number of trees based on individual genes supporting scleractinian monophyly, 335 naked coral or other topologies for maximum likelihood ( $\mathrm{ml}$ ) and Bayesian inference (bi) for 336 amino-acid (aa) and nucleotide alignments (nt). The majority of trees are consistent with 337 scleractinian monophyly, whereas few support the naked corals scenario. (b) Summary of the 338 concordance of phylogenetic inference for each gene. Each line represents a gene. The main 339 pattern (black lines) represents genes that are fully consistent with scleractinian monophyly, 340 whilst only a small proportion of genes consistently agree with the naked coral hypothesis (while 341 lines). The checkered lines correspond to genes producing topologies that are not consistent 342 across the different types of inference. The patterns are sorted from most abundant at the top of 343 the figure to least abundant at the bottom. c) Distribution of sequence lengths for genes 344 consistent with scleractinian monophyly (S, black lines in b)) and the naked coral hypothesis ( $\mathrm{N}$, 345 white lines b)). The sequences of the genes consistent with scleractinian monophyly are 346 significantly longer (Mann Whitney $\mathrm{U}$ test $\mathrm{p}=0.0004$ ). 
a)

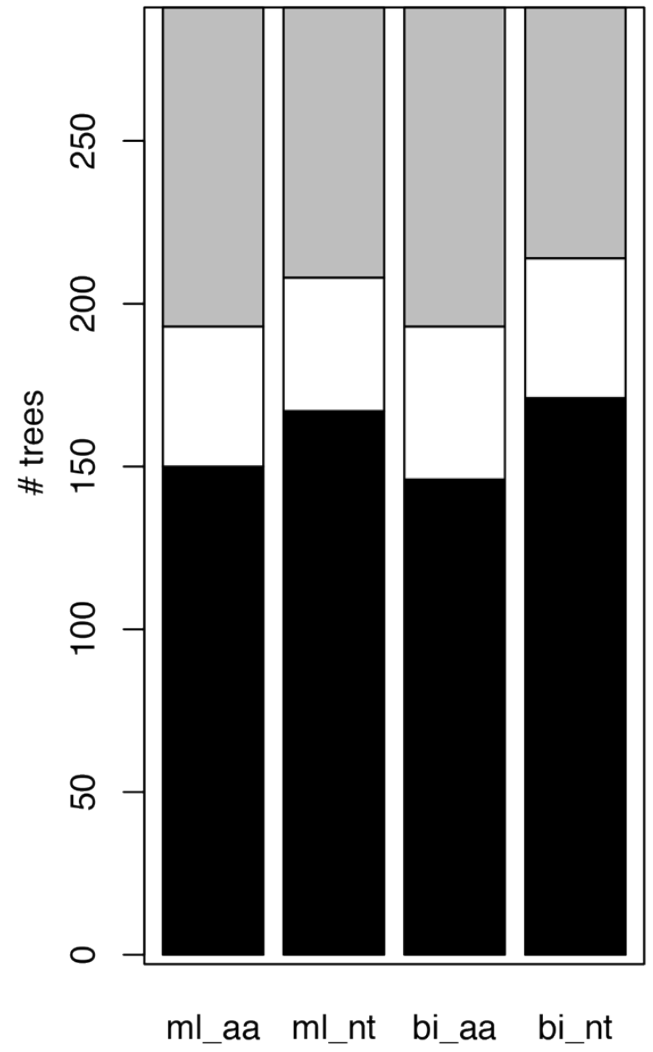

b)

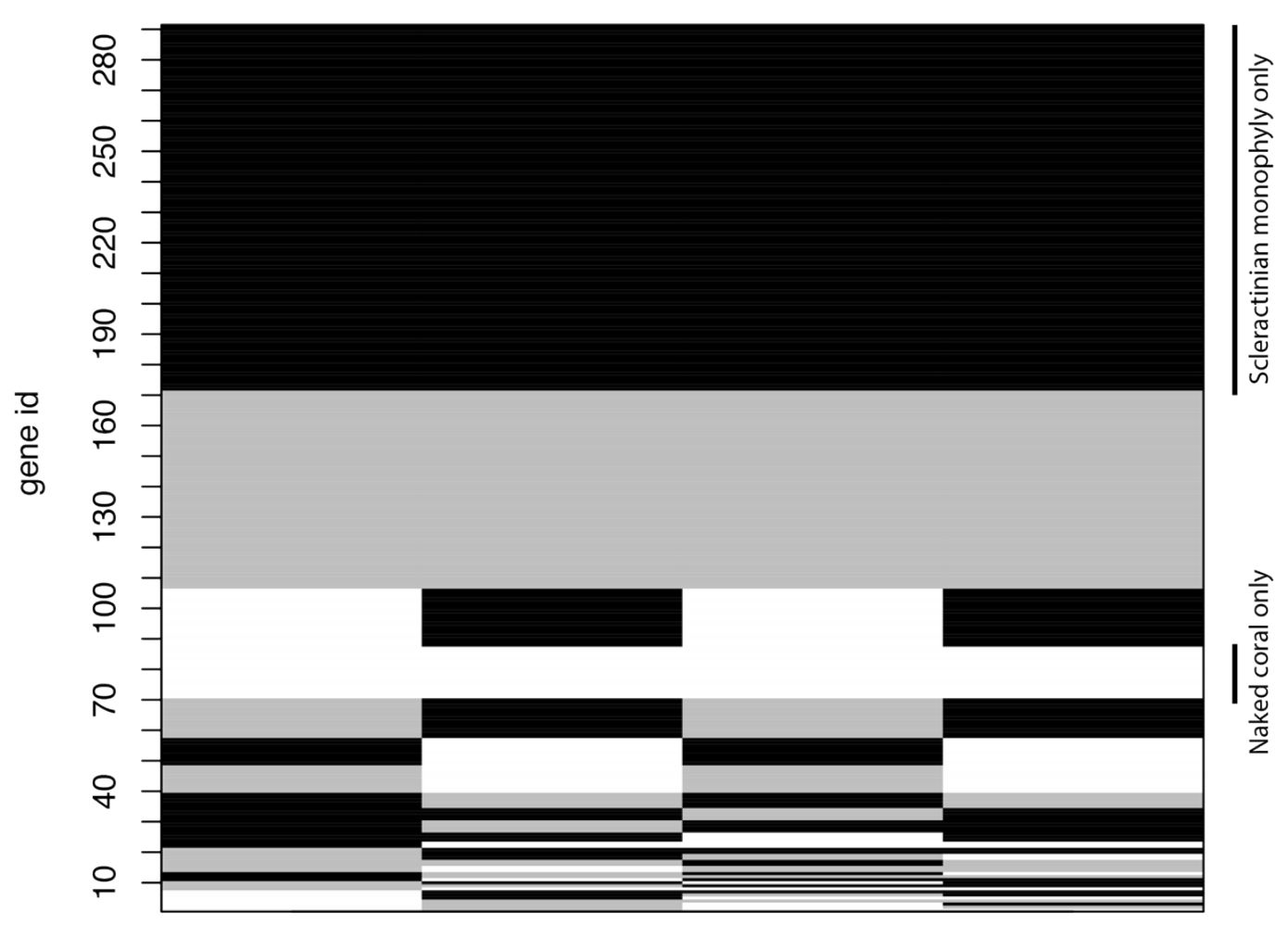

Scleractinian monophyly

c)

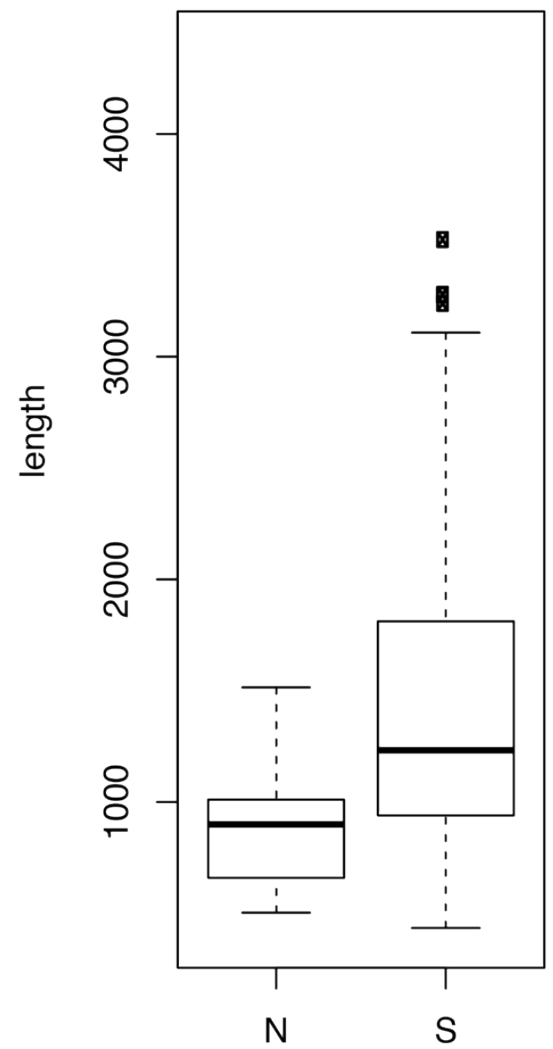

Naked coral Other 


\section{References}

351

352

353

354

355

356

357

358

359

360

361

362

363

364

365

366

367

368

369

370

371

372

373

374

375

376

377

378

379

380

381

382

383

384

385

386

387

388

389

390

391

392

393
Akanni WA, Creevey CJ, Wilkinson M, and Pisani D. 2014. L.U.St: a tool for approximated maximum likelihood supertree reconstruction. BMC Bioinformatics 15:183. 10.1186/1471-2105-15-183

Ane C, Larget B, Baum DA, Smith SD, and Rokas A. 2006. Bayesian Estimation of Concordance among Gene Trees. Molecular Biology and Evolution 24:412-426. $10.1093 / \mathrm{molbev} / \mathrm{msl} 170$

Aranda M, DeSalvo MK, Bayer T, Medina M, and Voolstra C. 2012. Evolutionary insights into scleractinian corals using comparative genomic hybridizations. Bmc Genomics 13:501.

Barbeitos MS, Romano SL, and Lasker HR. 2010. Repeated loss of coloniality and symbiosis in scleractinian corals. Proceedings of the National Academy of Sciences 107:1187711882. 10.1073/pnas.0914380107

Barbier EB, Moreno-Mateos D, Rogers AD, Aronson J, Pendleton L, Danovaro R, Henry LA, Morato T, Ardron J, and Van Dover CL. 2014. Protect the deep sea. Nature 505:475477.

Budd AF, Romano SL, Smith ND, and Barbeitos MS. 2010. Rethinking the Phylogeny of Scleractinian Corals: A Review of Morphological and Molecular Data. Integrative and Comparative Biology 50:411-427. 10.1093/icb/icq062

Capella-Gutierrez S, Silla-Martinez JM, and Gabaldon T. 2009. trimAl: a tool for automated alignment trimming in large-scale phylogenetic analyses. Bioinformatics 25:19721973. 10.1093/bioinformatics/btp348

Chapman JA, Kirkness EF, Simakov O, Hampson SE, Mitros T, Weinmaier T, Rattei T, Balasubramanian PG, Borman J, Busam D, Disbennett K, Pfannkoch C, Sumin N, Sutton GG, Viswanathan LD, Walenz B, Goodstein DM, Hellsten U, Kawashima T, Prochnik SE, Putnam NH, Shu SQ, Blumberg B, Dana CE, Gee L, Kibler DF, Law L, Lindgens D, Martinez DE, Peng JS, Wigge PA, Bertulat B, Guder C, Nakamura Y, Ozbek S, Watanabe H, Khalturin K, Hemmrich G, Franke A, Augustin R, Fraune S, Hayakawa E, Hayakawa S, Hirose M, Hwang JS, Ikeo K, Nishimiya-Fujisawa C, Ogura A, Takahashi T, Steinmetz PRH, Zhang XM, Aufschnaiter R, Eder MK, Gorny AK, Salvenmoser W, Heimberg AM, Wheeler BM, Peterson KJ, Boettger A, Tischler P, Wolf A, Gojobori T, Remington KA, Strausberg RL, Venter JC, Technau U, Hobmayer B, Bosch TCG, Holstein TW, Fujisawa T, Bode HR, David CN, Rokhsar DS, and Steele RE. 2010. The dynamic genome of Hydra. Nature 464:592-596.

Chen CA, Wallace CC, and Jackie W. 2002. Analysis of the mitochondrial 12S rRNA gene supports a two-clade hypothesis of the evolutionary history of scleractinian corals. Molecular Phylogenetics and Evolution 23:137-149.

Cohen AL, and Holcomb M. 2009. Why Corals Care About Ocean Acidification_Uncovering the Mechanism. Oceanography 22:118-128.

Daly M, Brugler MR, Cartwright P, Collins A, Dawson MN, Fautin DG, France SC, McFadden CS, Opresko DM, Rodriguez E, Romano SL, and Stake JL. 2007. The phylum Cnidaria: A review of phylogenetic patterns and diveristy 300 years after Linnaeus. Zootaxa 1668:127-182. 
394

395

396

397

398

399

400

401

402

403

404

405

406

407

408

409

410

411

412

413

414

415

416

417

418

419

420

421

422

423

424

425

426

427

428

429

430

431

432

433

434

435

436

437

438

Daly M, Fautin DG, and Cappola VA. 2003. Systematics of the Hexacorallia (Cnidaria : Anthozoa). Zoological Journal of the Linnean Society 139:419-437.

Darriba D, Taboada GL, Doallo R, and Posada D. 2012. jModelTest 2: more models, new heuristics and parallel computing. Nature Methods 9:772.

den Hartog JC. 1980. Caribbean shallow water Corallimorpharia.

Done TJ. 1999. Coral community adaptability to environmental change at the scales of regions, reefs and reef zones. American Zoologist 39:66-79.

Ebersberger I, Strauss S, and von Haeseler A. 2009. HaMStR: Profile hidden markov model based search for orthologs in ESTs. Bmc Evolutionary Biology 9:157. 10.1186/14712148-9-157

Ezaki Y. 1997. The Permian coral Numidiaphyllum: new insights into anthozoan phylogeny and Triassic scleractinian origins. Palaeontology 40:1-40.

Ezaki Y. 1998. Paleozoic Scleratinia: Progenitors or Extinct Experiments? Paleobiology 24:227-234.

Ezaki Y. 2000. Palaeoecological and phylogentic implications of a new scleractinian genus from Permian sponge reefs, South China. Paleontology 78:84-97.

Fine M, and Tchernov D. 2007. Scleractinian coral species survive and recover from decalcification. Science 315:1811. 10.1126/science.1137094

Fukami H, Chen CA, Budd AF, Collins A, Wallace C, Chuang YY, Chen C, Dai CF, Iwao K, Sheppard C, and Knowlton N. 2008. Mitochondrial and Nuclear Genes Suggest that Stony Corals Are Monophyletic but Most Families of Stony Corals Are Not (Order Scleractinia, Class Anthozoa, Phylum Cnidaria). Plos One 3:e3222.

Fukami H, and Knowlton N. 2005. Analysis of complete mitochondrial DNA sequences of three members of the Montastraea annularis coral species complex (Cnidaria, Anthozoa, Scleractinia). Coral Reefs 24:410-417. 10.1007/s00338-005-0023-3

Grabherr MG, Haas BJ, Yassour M, Levin JZ, Thompson DA, Amit I, Adiconis X, Fan L, Raychowdhury R, Zeng Q, Chen Z, Mauceli E, Hacohen N, Gnirke A, Rhind N, di Palma F, Birren BW, Nusbaum C, Lindblad-Toh K, Friedman N, and Regev A. 2011. Fulllength transcriptome assembly from RNA-Seq data without a reference genome. Nature Biotechnology 29:644-652. 10.1038/nbt.1883

Guinotte JM, Orr J, Cairns S, Freiwald A, Morgan L, and George R. 2006. Will human-induced changes in seawater chemistry alter the distribution of deep-sea scleractinian corals? Frontiers in Ecology and the Environment 4:141-146. Doi 10.1890/15409295(2006)004[0141:Whcisc]2.0.Co;2

Hoegh-Guldberg O, Mumby PJ, Hooten AJ, Steneck RS, Greenfield P, Gomez E, Harvell CD, Sale PF, Edwards AJ, Caldeira K, Knowlton N, Eakin CM, Iglesias-Prieto R, Muthiga N, Bradbury RH, Dubi A, and Hatziolos ME. 2007. Coral reefs under rapid climate change and ocean acidification. Science 318:1737-1742.

Honisch B, Ridgwell A, Schmidt DN, Thomas E, Gibbs SJ, Sluijs A, Zeebe R, Kump L, Martindale RC, Greene SE, Kiessling W, Ries J, Zachos JC, Royer DL, Barker S, Marchitto TM, Jr., Moyer R, Pelejero C, Ziveri P, Foster GL, and Williams B. 2012. The geological record of ocean acidification. Science 335:1058-1063. 10.1126/science. 1208277

Hughes L. 2003. Climate change and Australia: Trends, projections and impacts. Austral Ecology 28:423-443. 
439

440

441

442

443

444

445

446

447

448

449

450

451

452

453

454

455

456

457

458

459

460

461

462

463

464

465

466

467

468

469

470

471

472

473

474

475

476

477

478

479

480

481

482

483

Hughes TP, Baird AH, Bellwood DR, Card M, Connolly SR, Folke C, Grosberg R, HoeghGuldberg O, Jackson JBC, Kleypas J, Lough JM, Marshall P, Nystrom M, Palumbi SR, Pandolfi JM, Rosen B, and Roughgarden J. 2003. Climate change, human impacts, and the resilience of coral reefs. Science 301:929-933.

Huttley G. 2009. Do genomic datasets resolve the correct relationship among the placental, marsupial and monotreme lineages? Australian Journal of Zoology 57:167-174. 10.1071/ZO09049

Katoh K, and Standley DM. 2013. MAFFT Multiple Sequence Alignment Software Version 7: Improvements in Performance and Usability. Molecular Biology and Evolution 30:772-780.

Kiessling W, Simpson C, and Foote M. 2010. Reefs as Cradles of Evolution and Sources of Biodiversity in the Phanerozoic. Science 327:196-198. 10.1126/science.1182241

Kitahara MV, Cairns SD, Stolarski J, Blair D, and Miller DJ. 2010. A Comprehensive Phylogenetic Analysis of the Scleractinia (Cnidaria, Anthozoa) Based on Mitochondrial C01 Sequence Data. Plos One 5:e11490. 10.1371/journal.pone.0011490

Kitahara MV, Lin M-F, Foret S, Huttley G, Miller DJ, and Chen CA. 2014. The "Naked Coral" Hypothesis Revisited - Evidence for and Against Scleractinian Monophyly. PloSone 9:e94774. 10.1371/journal.pone.0094774.g001

Kitahara MV, Stolarski J, Cairns SD, Benzoni F, Stake JL, and Miller DJ. 2012. The first modern solitary Agariciidae (Anthozoa, Scleractinia) revealed by molecular and microstructural analysis. Invertebrate Systematics 26:303. 10.1071/is11053

Lanfear R, Calcott B, Ho SYW, and Guindon S. 2012. PartitionFinder: Combined Selection of Partitioning Schemes and Substitution Models for Phylogenetic Analyses. Molecular Biology and Evolution 29:1695-1701. 10.1093/molbev/mss020

Lartillot N, Rodrigue N, Stubbs D, and Richer J. 2013. PhyloBayes MPI: Phylogenetic Reconstruction with Infinite Mixtures of Profiles in a Parallel Environment. Syst Biol 62:611-615.

Li W, and Godzik A. 2006. Cd-hit: a fast program for clustering and comparing large sets of protein or nucleotide sequences. Bioinformatics 22:1658-1659.

Lin MF, Kitahara MV, Luo H, Tracey D, Geller J, Fukami H, Miller DJ, and Chen CA. 2014. Mitochondrial Genome Rearrangements in the Scleractinia/Corallimorpharia Complex: Implications for Coral Phylogeny. Genome Biology and Evolution 6:10861095. 10.1093/gbe/evu084

Medina M, Collins AG, Takaoka TL, Kuehl JV, and Boore JL. 2006. Naked corals: Skeleton loss in Scleractinia. Proceedings of the National Academy of Sciences of the United States of America 103:9096-9100.

Moberg F, and Folke C. 1999. Ecological goods and services of coral reef ecosystems. Ecological Economics 29:215-233.

Pandolfi JM, Connolly SR, Marshall DJ, and Cohen AL. 2011. Projecting coral reef futures under global warming and ocean acidification. Science 333:418-422. 10.1126/science.1204794

Pisani D, Cotton JA, and MacInerney JO. 2007. Supertrees Disentangle the Chimerical Origin of Eukaryotic Genomes. Molecular Biology and Evolution 24:1752-1760. 10.1093/molbev/msm095 
484

485

486

487

488

489

490

491

492

493

494

495

496

497

498

499

500

501

502

503

504

505

506

507

508

509

510

511

512

513

514

515

516

517

518

519

520

521

522

523

524

525

526

Putnam NH, Srivastava M, Hellsten U, Dirks B, Chapman J, Salamov A, Terry A, Shapiro H, Lindquist E, Kapitonov VV, Jurka J, Genikhovich G, Grigoriev IV, Lucas SM, Steele RE, Finnerty JR, Technau U, Martindale MQ, and Rokhsar DS. 2007. Sea anemone genome reveals ancestral eumetazoan gene repertoire and genomic organization. Science 317:86-94.

Ramirez-Llodra E, Tyler PA, Baker MC, Bergstad OA, Clark MR, Escobar E, Levin LA, Menot L, Rowden AA, Smith CR, and Van Dover CL. 2011. Man and the Last Great Wilderness: Human Impact on the Deep Sea. Plos One 6. ARTN e22588

10.1371/journal.pone.0022588

Romano S, and Palumbi S. 1996. Evolution of scleractinian corals inferred from molecular systematics. Science 271:640-642.

Romano SL, and Cairns SD. 2000. Molecular phylogenetic hypotheses for the evolution of scleractinian corals. Bulletin of Marine Science 67:1043-1068.

Roniewicz E, and Morycowa E. 1993. Evolution of the Scleractinia in the light of microstructural data. . Courier Forschungsinstitut Senckenberg 164:233-240.

Ronquist F, and Huelsenbeck JP. 2003. MrBayes 3: Bayesian phylogenetic inference under mixed models. . Bioinformatics 19:1572-1574.

Scrutton CT. 1993. New kilbuchophyllid corals from the Ordovician of the Southern Uplands, Scotland. Courier Forschungsinstitut Senckenberg 164:153-158.

Scrutton CT, and Clarkson ENK. 1991. A new scleractinian-like coral from the Ordovician of the Southern Uplands, Scotland. Palaeontology 34:179 -194.

Sheffield NC, Song H, Cameron SL, and Whiting MF. 2009. Nonstationary evolution and compositional heterogeneity in beetle mitochondrial phylogenomics. Syst Biol 58:381-394. 10.1093/sysbio/syp037

Shinzato C, Shoguchi E, Kawashima T, Hamada M, Hisata K, Tanaka M, Fujie M, Fujiwara M, Koyanagi R, Ikuta T, Fujiyama A, Miller DJ, and Satoh N. 2011. Using the Acropora digitifera genome to understand coral responses to environmental change. Nature 476:320-323.

Stamatakis A. 2006. RAxML-VI-HPC: maximum likelihood-based phylogenetic analyses with thousands of taxa and mixed models. Bioinformatics 22:2688-2690.

Stanley GDJ, and Fautin DG. 2001. The Origins of Modern Corals. Science 291:1913-1914.

Stanley JGD. 2003. The evolution of modern corals and their early history. Earth-Science Reviews 60:195-225.

Stolarski J, Kitahara MV, Miller DJ, Cairns SD, Mazur M, and Meibom A. 2011. The ancient evolutionary origins of Scleractinia revealed by azooxanthellate corals. Bmc Evolutionary Biology 11:316. 10.1186/1471-2148-11-316

Veron JEN. 1995. Corals in Space and Time: The Biogeography and Evolution of the Scleractinia. Sydney: University of New South Wales Press.

Wells J. 1956. Scleractinia. Lawrence: University of Kansas Press.

Xia X. 2013. DAMBE5: A comprehensive software package for data analysis in molecular biology and evolution. Molecular Biology and Evolution 30:1720-1728. 